\title{
Pseudo-Geological Impediments to Implementation of Revolutionary Technologies with Societal Analogues
}

In a previous POSTERMINARIES, ${ }^{1}$ we complained about automation of the automobile because the human touch was being trampled. Both readers who agree and disagree may attribute this reaction to an overdose of nostalgia. Perhaps so! And perhaps if my views were pervasive (little chance of that!), they would impede the progress of automation. The real impediment, however, to the introduction of truly radical innovation is not sentiment, but sediment. ${ }^{2}$

Sediment, for example, is the U.S.'s television broadcast standard, NTSC. Once adopted and implemented, it can't be easily replaced or even substantially improved. The huge investment in it and in the large number of current features built on it would be disrupted were it to be changed now. As technology moves inexorably onward, augmentations to the current system become technically feasible in their own right but are incompatible with NTSC. Not just the revolutionary but the modest incremental improvements in this bind remain unavailable to us, the viewers, because of a decision taken long before these innovations were envisioned.

I resist pointing to the internal combustion engine as an example of sediment because I like my car the way it is. A better example is the DOS ${ }^{\circledR}$ operating system on the ubiquitous PC. A veritable pyramid of applications and/or operating environments like Windows ${ }^{\circledR}$ rests on $\mathrm{DOS}^{\circledR}$ and each is constrained by the $\mathrm{DOS}^{\circledR}$ foundation. The reverse is the insidious part-DOS ${ }^{(B)}$ itself is constrained by the havoc any incompatible upgrade in it would cause. Thus it is sediment. It seems that the ensemble of technological choices entrenched in a sedimentary stratum is under such great pressure from the towering applications it supports, it becomes, in truth, metamorphic.

This is an unstable situation in an age of progress. The very same customers who demand ever-increasing capabilities from designers and manufacturers cry foul at the first suggestion that the next release of a favorite software package won't understand prior command syntax or that the forthcoming series of improved lenses won't mate to earlier camera bodies. This dynamic guarantees that occasional corrections, not dissimilar to the stock market correction of 1929, will occur. Once retrofit becomes synonymous with retrograde, the first crack develops in the sedimentary layer. Then the state-of-the-art is poised to lurch forward. Concepts such as selforganized criticality ${ }^{3}$ and catastrophe theory ${ }^{4}$ may apply nicely to this phenomenon. As gradual changes to certain dynamical systems accumulate, an abrupt change unavoidably looms. Lanier's point ${ }^{2}$ is that the groundwork we lay now for the infrastructure of the information highway will either be a blessing or a curse for a very long time, so it behooves us to get it right.

If you say that anyone worth his salt knows that early choices limit future degrees of freedom; that the more fundamental the choices and the larger the system they affect, the more impossible they are to undo ${ }^{2}$; and, if you exclaim, "what's so improbable about sediment?" I would say, "the enunciation of the trivially obvious can provide valuable insight."

The notion of sediment is not confined to technology. It clearly maps onto human affairs. In good and settled times, we call it ballast. A steadying influence on our course that blunts unreasonable excursions into the impractical or hyperbolic. I.e., it discourages everyone from rocking the boat. In times demanding change, however, our ballast is instead tantamount to inertia, intransigence, the conservator of the status quo, and job-preserving digging in of heels. I.e., it discourages everyone from rocking the boat.

These may be cogent descriptions of alternative instantaneous conditions, but on the grand scale of eons, or even the not-so-grand scale of human history, one sees the stati quo periodically swept away by the confluence in space and time of history-making events. ${ }^{5}$ In short, present and imminent capabilities in computer and communications technologies coupled to mushrooming accessibility of this power to the masses (in which I am proud to count myself) are about to cause a catastrophic bifurcation of our historiographic trajectory no less significant than Alexander's conquest of the known world.

Thus we have a wind at our back and dare not ignore Lanier's warning lest our future sediment be designed for us by untamed forces of history. Who shall arbitrate change in the sediment? Which advocates of rule breaking, of derogating and casting off tired ways of doing, of living, will pave the next century? Will future sediment limit or protect us? Pretty deep questions to be asking about my TV, my telephone, and my PC. But if the technological choices mimic societal choices, chaos may result. Some say those who advocate "contempt for rules...strike at the sense of connectedness that any society needs to cohere...." 6 I say that our future connectedness literally depends on our redesigning the rules now. Of course, after enough eons pass, entropy's increase will erase any trace of our struggle to organize our future (if you believe in thermodynamics). While we can still influence our local entropy, however, we should set about defining twenty-first century algorithms that will defy obsolescence.

E.N. KAUFMANN

1. E.N. Kaufmann, "The Eroding Feeling of the Road or Controlling Our Conveniences While Being Driven to Distraction by Prodigious Inanimate Objects that Know Not the Price of Progress," MRS Bulletin, Vol. XX, No. 7. (July 1995) p. 64.

2. Jaron Lanier, "Karma Vertigo: or Considering the Excessive Responsibilities Placed on Us by the Dawn of the Information Infrastructure," on the World Wide Web at http:/ / www. well.com/community/Jaron.Lanier.

3. P. Bak and M. Creutz, "Dynamics of Sand," MRS Bulletin, Vol. XVI, No. 6 (June 1991) pp. 17-21.

4. R. Thom, "Structural Stability and Morphogenesis: An Outline of a General Theory of Models," (W.A. Benjamin, Reading, Mass., 1975); E.C. Zeeman, "Catastrophe Theory: Selected Papers, 1972-1977," (Addison-Wesley Pub. Co., Reading, Mass., 1977).

5. Ralph H. Abraham, Euclid's Voyage (a hyperbook) (TELOS, The Electronic Library of Science, Springer-Verlag, Santa Clara, Calif., 1994) on the World Wide Web at http:/ / hypatia. ucsc.edu:70/Oh/EUCLID2/Preliminaries/ch3 .html.

6. John Leo, U.S. News $\mathcal{E}$ World Report (August 28/September 4, 1995) p. 31 